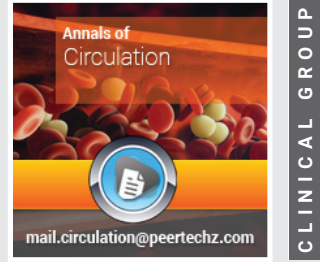

\title{
Duplex ultrasound in upper and lower limb deep venous thrombosis
}

\section{Tsongo V Sosthène ${ }^{1 *}$, Kahatwa K Serge ${ }^{2}$, Kabuyaya K Medard ${ }^{3}$, Kighoma V Simplice ${ }^{4}$, Musubao K John ${ }^{4}$ and Serugendo S Albin 5}

1MMED RAD, Makerere University Kampala (MUK), HEAL Africa Hospital, Department of Radiology, Lecturer at University of Great Lakes' Countries (ULPGL), Goma, D.R.Congo

2MMED, MUK, Department of Internal Medicine, HEAL Africa Hospital, D.R Congo, Goma

${ }^{3}$ Department of Surgery, MMED General Surgery, University of Rwanda, HEAL Africa Hospital, D.R Congo, Goma

${ }^{4}$ Department of Orthopaedics \& Traumatology, MMED in Orthopaedics \& Traumatology, MUK, HEAL Africa Hospital, D.R Congo, Goma

${ }^{5}$ Department of Internal Medicine, MMED, MUK, HEAL Africa Hospital, D.R Congo, Goma

Check for updates

Received: 17 December, 2019

Accepted: 10 February, 2020

Published: 12 February, 2020

*Corresponding author: Tsongo Vululi Sosthène, MMED RAD, Makerere University Kampala (MUK), HEAL Africa Hospital, Department of Radiology, Lecturer at University of Great Lakes' Countries (ULPGL), Goma, D.R.Congo, Phone No: +243994215947 ,

E-mail: sosthenetsongo@gmail.com

Keywords: Duplex ultrasound; Doppler imaging; Upper/lower limb deep veins anatomy; Deep venous thrombosis and Well's score

https://www. peertechz.com

\begin{abstract}
Duplex ultrasound involves B-mode and Doppler ultrasound. Duplex ultrasonography is a radiological examination requested by clinicians in patients with symptoms of deep venous thrombosis such as upper or lower limb swelling, pain and tenderness. Deep venous thrombosis is a pathology in which clot formation causes obstruction of blood flow. The lower limbs are more affected by DVT than upper limbs. Several radiological investigations may be helpful to make the diagnosis. Ultrasound remains a non-ionic, non-invasive, cheaper, available and accurate investigation for prompt diagnosis of DVT however Duplex USG must be done by a radiologist or an experimented sonographer. The sonographic findings may be of acute or chronic DVT. In acute DVT, the intra luminal blood clot is hypoechoic or anechoic whereas in chronic DVT, it is hyperechoic with peripheral revascularization on color Doppler imaging. The results of Doppler ultrasound are sent to clinicians for good treatment plan and follow-up. The treatment is urgent in acute DVT to prevent pulmonary embolism, a life-threatening complication with high mortality rate.
\end{abstract}

\section{Introduction}

Duplex ultrasonography is useful to diagnose DVT and subsequently prevent pulmonary embolism. The awareness of risk factors, clinical and sonographic findings lead to accurate diagnosis of DVT [1,2]. This section is focused on the role of Duplex USG in the diagnosis of upper or lower extremity DVT. The examination requires basic knowledge of upper or lower limb deep venous anatomy and skills in ultrasound scan technique [3]. There is no need of patient's preparation for this examination. The examination may be done in thirty to forty-five minutes. The technique includes B-mode, compression ultrasound and Doppler ultrasound scan [1]. The sonographic patterns of different types of DVT are discussed below. Treatment plan and follow up are mandatory to prevent PE. Several studies have been done on DVT; findings of those oriented in the domain of ultrasonography are discussed below.

\section{Duplex ultrasound in upper and lower limb deep venous thrombosis}

\section{Recall of upper and lower limb deep venous anatomy}

The upper limb deep venous anatomy: The upper limb is drained by superficial and deep veins. The cephalic vein receives blood from the arm through superficial cephalic vein and basilica vein. The cephalic vein is located in the subcutaneous fat of the lateral aspect of the arm. 
The deep venous system is situated medially. The cephalic vein joins the axillary vein which drains blood in the subclavian vein. Blood from the medial aspect of the arm is drained by the basilic vein joining the paired brachial veins at the level of the teres major muscle then the axillary vein laterally. The axillary vein drains blood into the subclavian vein. The medial portion of the subclavian vein receives the smaller external jugular vein and the larger internal jugular vein in the base of the neck to form the brachiocephalic (innominate) vein [3].

The lower limb deep venous anatomy: The venous system of the lower extremity drains blood from the foot to the inguinal region through superficial and deep veins. The lower limb deep veins follow the course of the corresponding arteries. The deep veins of the leg at the calf include the anterior tibial, posterior tibial, and peroneal veins which present as pairs on both sides of the artery. Anatomical variant of the deep venous system is noted particularly duplication variants. The posterior tibial vein drains the posterior aspect of the leg and plantar surface of the foot. It receives blood from the medial and lateral plantar vein. The posterior tibial vein is located behind the tibia and joins the popliteal vein at the popliteal fossa. The anterior tibial vein receives blood from the dorsal pedal vein. It lies along the anterior compartment of the leg just above the interosseous membrane between the tibia and the fibula. It joins the posterior tibial vein to form the tibioperoneal trunk and popliteal vein. The peroneal vein runs along the posteromedial aspect of the fibula and joins the posterior tibial vein.

The popliteal vein is the upward continuation of the anterior and posterior tibial veins at the posterior knee. It receives blood from the deep vein system of the foot and the calf. It lies along the posterior aspect of the knee and the distal aspect of the antero-medial thigh. The popliteal vein is superficial to the artery at the posterior knee. It is located medial to the artery in the popliteal fossa.

The distal part of the femoral vein receives blood from the popliteal vein. It lies into the adductor hiatus. The anatomists no longer recommend the term superficial femoral vein as this vein is not part of the superficial veins. The term superficial femoral vein is replaced by femoral vein. In the lower part, the femoral vein lies laterally to the artery; in the mid-part, behind the artery; and in the upper part, medial to the artery. The deep femoral vein from the inner thigh, running along the deep femoral artery, joins the femoral vein and forms the common femoral vein, which is adjacent to the common femoral artery. The common femoral vein is located on the medial side of the artery. The inguinal ligament is the landmark that divides the common femoral vein from the external iliac vein.

Great and small saphenous veins are the two major superficial veins of the lower extremity. The great saphenous vein joins the common femoral vein at the saphenofemoral junction, a few centimeters distal to the inguinal ligament. The terms "greater saphenous vein," "long saphenous vein," "lesser saphenous vein" and "short saphenous vein" are no longer recommended for the purpose of standardizing terminology [3-5].

\section{Risk factors for DVT and clinical findings}

Deep vein thrombosis is the medical condition in which blood clot is formed in the deep veins [6]. There are numerous risk factors leading to blood clot formation.

Classically, the risk factors are summarized in Virchow triad. Many years ago, Rudolf Virchow described three risk factors associated with venous thrombosis development. The triad of Virchow involves venous blood flow stasis, hypercoagulability and endothelial injury. Several studies in the domain of venous thromboembolism revealed so many risk factors according to different categories of patients, their history, health status and treatment received $[6,7]$.

Risk factors include age, bed rest, congestive heart failure, estrogen, family history, hematologic cancers, HIV patients on ART with high viral load, prolonged immobility, indwelling catheters, long-distance travel, major trauma, noninfectious inflammatory conditions, obesity, pregnancy (and postpartum status), history of Venous Thromboembolism (VTE), recent surgery, smoking, solid cancers, stroke, and thrombophilia. History of DVT increases the risk of recurrence. About $30 \%$ of patients who have had DVT will have it again [7].

Symptoms depend on the type of DVT. The ability to characterize DVT as acute or chronic is a difficult clinical problem. The signs and symptoms of acute DVT include pain, erythema, and swelling. Tenderness may be present along the course of the involved veins, and a cord may be palpable especially in superficial vein thrombosis. There may be increased tissue turgor, distention of superficial veins, and the appearance of prominent venous collaterals. In some patients, deoxygenated hemoglobin in stagnant veins imparts a cyanotic hue to the limb, a condition called phlegmasia cerulean dolens. In markedly edematous legs, the interstitial tissue pressure may exceed the capillary perfusion pressure, causing pallor, a condition designated phlegmasia alba dolens. The most common complaint in suspected DVT of the calf is pain. Homans' sign is positive. The knee is in the flexed position then forcibly dorsiflexion of the ankle cause calf pain. Pain in the calf with this maneuver may be consistent with the diagnosis of deep venous thrombosis $[8,9]$.

The local symptoms are due to obstruction or phlebitis:

-Warmth

-Swelling: it is important to measure the circumference of the leg or the arm for follow-up.

-Deep crampy pain in affected extremity usually worse in erect position.

-Tenderness along course of affected vein

-Homans sign: calf pain upon compression of sole of foot.

About 2/3 of DVT are asymptomatic. Clinically suspected DVT is accurate in only $26 \%-45 \%$.

Wells score is DVT probability calculation based on clinical findings [10-12]. 
-Paralysis, paresis or recent orthopedic casting of lower extremity (1 point)

-Recently bedridden (more than 3days) or major surgery within past 4weeks (1 point)

-Localized tenderness in deep vein system (1 point)

-Swelling of entire leg (1 point)

-Calf swelling $3 \mathrm{~cm}$ greater than other leg (measured $10 \mathrm{~cm}$ below the tibial tuberosity) (1 point)

-Pitting edema greater in the symptomatic leg (1 point)

-Collateral non varicose superficial veins (1 point)

-Active cancer or cancer treated within 6 months (1 point)

-Alternative diagnosis more likely than DVT (Baker's cyst, cellulitis, muscle damage, superficial venous thrombosis, post phlebitic syndrome, inguinal lymphadenopathy, external venous compression) $(-2$ points)

\section{DVT Risk Score Interpretation}

$$
\begin{array}{ll}
\text { 3-8 Points: } & \text { High probability of DVT } \\
\text { 1-2 Points: } & \text { Moderate probability } \\
\text {-2-0 Points: } & \text { Low Probability }
\end{array}
$$

\section{Duplex ultrasound in upper and lower limb DVT}

Indications: Patient with clinical symptoms of DVT should undergo ultrasound scan of the affected limb. Asymptomatic patients with high risk for DVT should also benefit from Duplex Ultrasonography (USG).

Studies have shown that some patients with absence of clinical symptoms for DVT may develop venous thrombosis. It is advised to perform ultrasound scan in patients with known risk factors for DVT. Study done in HIV positive patients on ART attending an outpatient clinic at Mulago Hospital in Uganda revealed a DVT prevalence of $9.1 \%$ [13].

Technique: Duplex ultrasound requires knowledge in ultrasound scan and a good ultrasound machine with color Doppler. The examination is done by a radiologist or a sonographer with skills in Doppler studies $[6,14]$.

There is no need of patient preparation.

The radiologist or the sonographer will explain to the patient the examination in the purpose to get his consent and cooperation while doing the scan.

Ultrasound scan of upper limb venous system is different from USG of lower limb deep veins because of the anatomy and patients positions however the principles are similar. Deep venous system of the leg in patients with suspected acute DVT is primarily evaluated on gray-scale imaging. Venous compression in the transverse plane and color flow Doppler sonography are frequently added for complete evaluation of the deep veins (Figure 1).

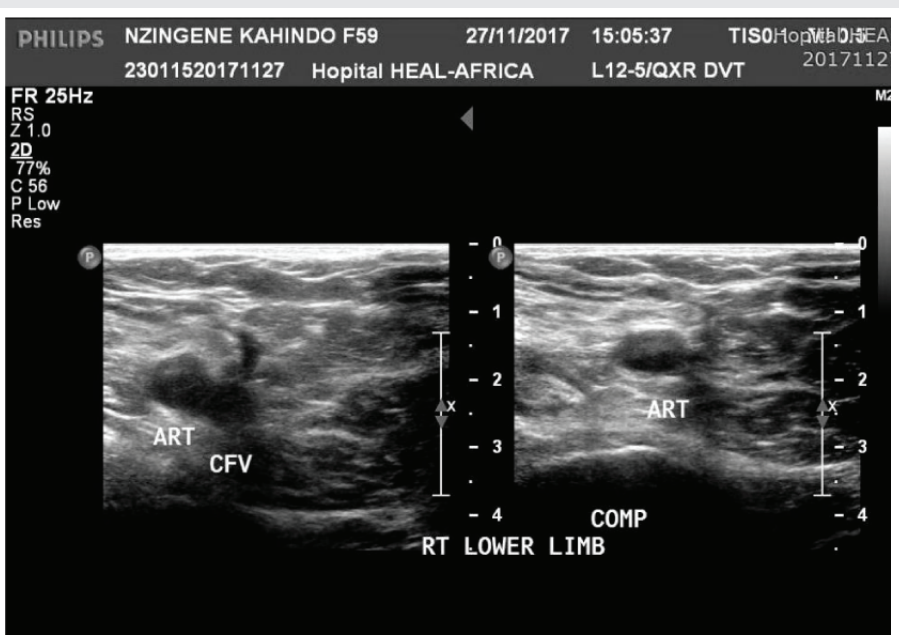

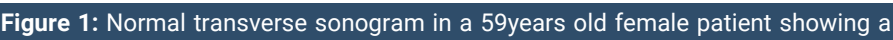
fully compressible common femoral vein. CFV is free of thrombus.

\section{Gray-Scale Imaging}

This ultrasound scan requires a higher frequency transducer. In most patients, a 7-12 $\mathrm{MHz}$, linear, phased array transducer which optimizes gray-scale imaging of the femoropopliteal and subclavian veins. The choice of the frequency of the probe depends on the size of the limb. In large patients, or when the iliac veins or the inferior vena cava must be evaluated to determine the superior extent of thrombus, a $6 \mathrm{MHz}$ or $4 \mathrm{MHz}$ transducer may be necessary to obtain adequate depth of penetration. Higher-frequency, $9 \mathrm{MHz}$ or $15 \mathrm{MHz}$ transducers optimize visualization of more superficial veins, such as the great and small saphenous, brachial, and inferior calf veins. As in all areas of sonography, the highest frequency transducer that gives adequate depth of penetration should be used to optimize spatial resolution [6].

Routinely the examination starts with interrogation of the internal jugular, brachiocephalic, subclavain, axillary, brachial, and basilica veins of the affected upper limb. During examination, we also evaluate the cephalic vein at its confluence with the subclavian vein. In some patient, this may be difficult to visualize. Deep veins of the forearm are also interrogated when symptoms of venous thrombosis are noted [15-17].

Compression of the deep veins is mandatory because lack of compressibility is a key sign to make the diagnosis of venous thrombosis even if the thrombus is not clearly seen. Compression is performed in the transverse plane because the transducer may slide off the vessel in the longitudinal axis, potentially resulting in a false-negative finding.

Additional color flow study is done to assess venous blood flow of the suspected deep veins. In case of venous thrombosis, there is absence or reduction of blood flow. 
Focal vascular stenosis is assessed by duplex sonography using color and spectral Doppler scan. The arteries adjacent to the veins are also examined looking for arterial stenosis or other abnormality.

Ultrasound of the lower limb deep veins is performed while the patient lies on the bed in decubitus position; limb in adduction with partial flexion of the leg.

The examination starts with interrogation of the external iliac vein, the common iliac vein, deep femoral vein, the femoral vein, the popliteal vein and its tributaries. The greater saphenous is also interrogated at the sapheno-femoral junction. In case the thrombus is seen in the CFV, its extension in the great saphenous vein is also evaluated (Figure 2).

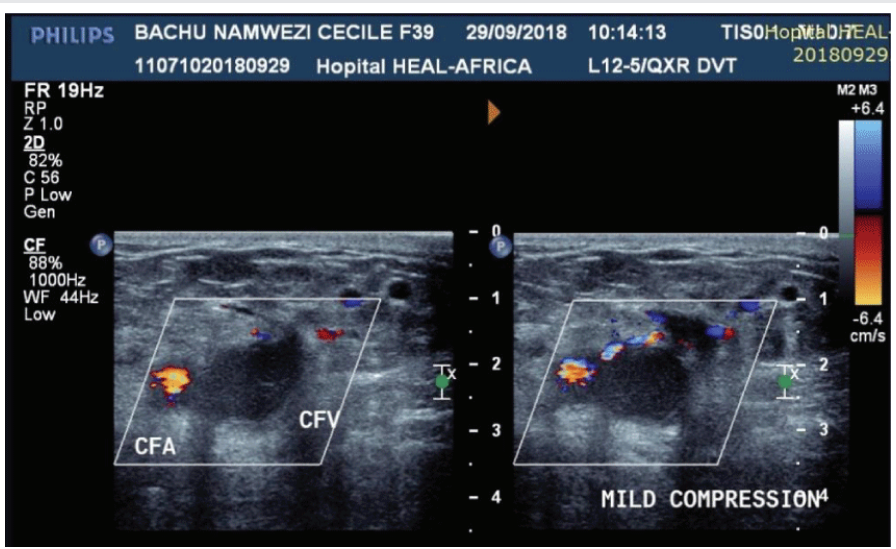

Figure 2: Transverse sonogram in a 39years old female patient with acute DVT. Hypoechoic thrombus is seen in the common femoral vein causing lack of compressibility and reduction of blood flow on Duplex ultrasonography. There is extension of thrombus in the great saphenous vein.

B-mode scan helps to evaluation the echotexture of the deep veins, to visualize the thrombus in the lumen and the caliber of the veins.

Compression technique of deep veins is usually important to confirm the diagnosis even if the thrombus is not seen. It is difficult to visualize hypo echoic clot in early acute phase.

Color flow and spectral studies are also done in lower limb deep veins. Knowledge of the normal spectral waveform in the upper extremity vein is essential in the examination of these veins. In case of dilatation of deep veins, we also do Valsava maneuver and augmentation maneuver looking for venous insufficiency [18-20].

Sonographic patterns of DVT: Duplex ultrasound is very helpful examination in the diagnosis of DVT which may be acute or chronic. Latent DVT has been noted in some category of patients such as HIV positive patients on ART [13]. Normal sonographic findings help the clinician to investigate further diseases with similar clinical signs. Normal Duplex ultrasound is noted in the absence of thrombus, fully venous compressibility and normal blood flow on color and pulse Doppler imaging (Figure 1).
Acute DVT: Sonographic findings in upper and lower limb acute DVT show same patterns. Gray scale images visualize the thrombus in the lumen of deep vein with variable echogenicity. The thrombosed vein is usually dilated and filled with the thrombus. The thrombus is hypoechoic unfortunately some acute thrombi are anechoic (Figure 2). It is usually difficult to visualize anechoic thrombus. Lack of complete venous compressibility is the hallmark sonographic sign of DVT $[21,22]$. The affected deep vein is initially dilated however as the thrombus ages, it resumes its normal caliber. Changes in vein caliber with respiration and the Valsalva maneuver are not seen in the majority of patients with DVT. This finding is present only in the proximal thigh, so it is not usually helpful below the bifurcation of the common femoral vein. The location of thrombus above or below the knee helps to investigate the risk of Pulmonary Embolism (PE) knowing that proximal DVT has a higher risk of PE. In extensive DVT, the thrombus is seen in the external iliac vein or in the great saphenous vein. Thrombus may also be seen in superficial veins [23-26].

On color Doppler sonography, flow is usually absent in the area of the thrombus. Peripheral blood flow is also outlined by color Doppler imaging. Collaterals are often visualized as prominent venous structures in the soft tissues surrounding the thrombosed main vein. Spectral analysis is useful in the evaluation of central deep venous thrombosis in which the anechoic thrombus may be difficult to identify. In some cases, reduction of blood flow and lack of venous compressibility are enough to diagnose DVT. Color flow Doppler ultrasound in patients with DVT shows either a persistent filling defect or thrombus in the color column seen in the lumen or the absence of color flow. Color Doppler is most helpful in deep segments of the thigh, pelvic, and calf veins $[27,28]$.

Chronic DVT: It is often clinically difficult to differentiate acute from chronic DVT. Initially the thrombus is either anechoic or hypoechoic then it becomes hyperechoic after changes within the lumen of the affected deep vein including clot retraction, chronic occlusion and wall thickening (Figure 3). Poor visualization of the thrombus and partial compressibility are noted. The thrombus may be adherent to the thickened vessel wall. Diagnosis of chronic DVT does not rely on compression sonography only knowing that it may lead to false positive cases due to thickening of vessel wall following phlebitis. Color flow Doppler ultrasound often plays a big role in differentiating acute from chronic DVT. In most of patients, partial compressibility and peri thrombotic blood flow are seen in chronic DVT [29,30]. Findings suggestive of chronic DVT with color flow Doppler imaging include irregular echogenic vein walls, thickening of the vein walls due to retracted thrombus, calcified retracted thrombus, decreased diameter of the venous lumina, atretic venous segments, well-developed collateral veins, associated deep venous insufficiency, and absence of distended veins containing hypoechoic or isoechoic thrombus [31]. Recanalization of the vein after an acute thrombotic event is noted in chronic DVT. Blood flow is seen around hyperechoic thrombus.

Discussion of study findings: Diagnosis of DVT of the extremities requires a good clinical examination followed by 


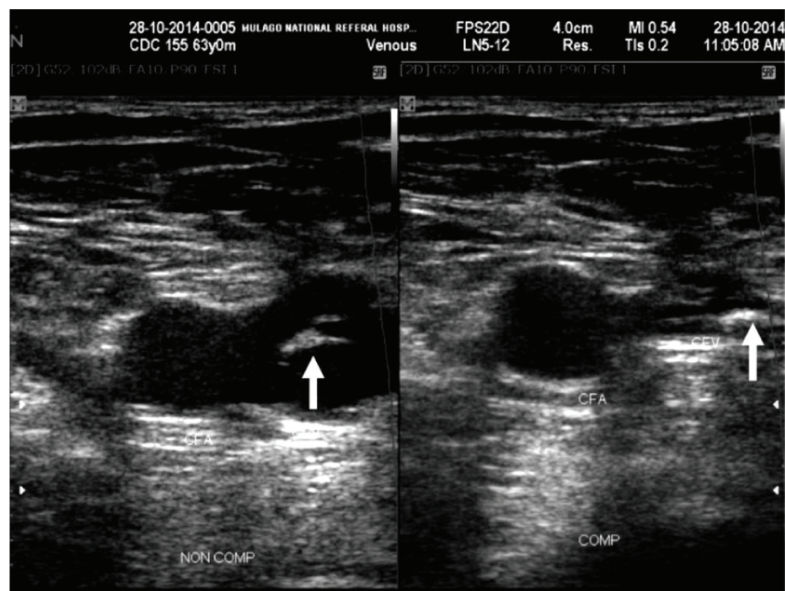

Figure 3: Chronic DVT. Transverse sonogram of 63 years old male HIV positive patient on HAART shows echogenic thrombus (white arrow) in the right common femoral vein (CFV) causing partial compressibility of the vein.

a radiological examination for confirmation of the diagnosis. Several radiological studies have been used for the diagnosis of DVT such as duplex ultrasound scan, contrast venography, CT scan venography and MRI venography [32].

Duplex Ultrasound is the initial imaging modality of choice for diagnosing DVT. It is non-invasive, cheaper, available, does not require nephrotoxic contrast agents and reproducible technique with high sensitivity and specificity. It doesn't use ionizing radiation. Furthermore, duplex ultrasound can be performed at the bed-side and is widely available.

The cephalic, axillary and subclavian veins are well demonstrated on ultrasound scan. The iliac vein, common femoral vein, deep femoral vein, femoral vein, popliteal vein and tributaries are also well seen on ultrasound. Noncompressibility of venous segment, intraluminal thrombus and flow abnormality are sufficient for the diagnosis of DVT of the upper extremities [33]. This modality is not used for suspected thrombus in the brachiocephalic vein and above the external iliac vein visible only on venography and magnetic resonance angiography. Radiologists have approved to consider duplex USG as initial investigation in patients with DVT however this examination shows limitation in upper limb thrombosis. Study findings have shown that sensitivity and specificity of duplex ultrasonography were $82 \%$ (95\% CI, $70 \%$ to $93 \%$ ) and $82 \%$ ( $95 \%$ CI, $72 \%$ to $92 \%$ ), respectively [34]. Other study showed that duplex USG is a rapid, accurate, and noninvasive technique in the evaluation of venous thrombosis in the upper extremity. It remains the modality of choice in screening for UEDVT [35]. However, MR or contrast venography may be helpful in select cases when sonographic findings are non-diagnostic or equivocal or when clinical suspicion for UEDVT remains high despite normal Doppler findings [36].

Lower Extremity Deep Venous Thrombosis (LEDVT) is well investigated on duplex ultrasound. Several studies have shown that compression ultrasound is accurate in the diagnosis of LEDVT. This method may be used as a screening test in patients with high risk of DVT. Early diagnosis will help to prevent pulmonary embolism (PE), a life-threatening complication which has a high mortality rate [6].
Study findings revealed a prevalence of DVT of $9.1 \%$ in HIV positive patients on ART attending an outpatient clinic at Mulago Hospital in Uganda. Majority of patients found with DVT had clinical symptoms of this pathology and only few patients had latent DVT (2.3\%). Almost half of HIV patients with DVT (48.6\%) had a lower Wells score for DVT therefore this study recommend a screening duplex ultrasound scan in HIV positive patients on ART second line history of prolonged immobility and low CD4 count (<200 cells/ $/ \mathrm{ll})$ [13].

Other studies showed that Well's score remains helpful to clinicians for good selection of patients who may undergo duplex ultrasound however a screening compression ultrasound scan combined with color Doppler is still useful for early diagnosis and prevention of complications [37]. Compression US has been procedure of choice for investigation of suspected upper and lower extremity DVT for decades. Other modification to this technique like two-point compression US, extended compression US (and complete compression US are used in different combinations at different institutions [33]. Compression ultrasonography is highly sensitive and specific modality for diagnosing LEDVT [29-38].

Studies have shown that contrasted venography is standard in the diagnosis of DVT when ultrasound scan is negative in asymptomatic patients for the pathology [39]. Normal findings of lower or upper limb duplex ultrasound do not exclude the possibility of venous thrombosis. Contrast venography is a radiological procedure performed using approximately $20 \mathrm{ml}$ iodinated contrast in a concentration of $240-300 \mathrm{mg}$ I/ $\mathrm{ml}$. Venography demonstrates the venous anatomy very well therefore a thrombus is well seen as a filling defect. It is often difficult to insert a cannula in an edematous limb while doing the procedure. Some patients may also present allergic reaction to iodinated contrast agents therefore venography should be done only if suspicion of DVT remains high despite negative USG [33].

Magnetic Resonance Angiography remains an accurate, noninvasive imaging modality for diagnosing DVT in the central thoracic veins such as superior vena cava and brachiocephalic vein. This radiological investigation correlates extremely well with contrast venography. It provides complete assessment of central collaterals and venous blood flow [33].

CT scan Venography has the ability to detect central thrombus especially in brachiocephalic vein thrombosis. It is able to demonstrate the extension of proximal lower limb DVT in iliac veins and inferior vena cava. This imaging modality requires injection of contrast media gent. Hence patients with history of allergy to iodine should undergo MRA or USG [33].

Although the accuracy of contrast venography is high than Duplex ultrasound for diagnosing of upper or lower limb DVT, studies have shown that USG remains useful as an initial radiological investigation looking for thrombus in deep veins. Noninvasive duplex USG has replaced contrast venography as the gold standard for screening of LEDVT. The sensitivity for thrombosis detection is about $97 \%$, with a high negative predictive value $(98 \%)$ when compression ultrasound is complemented by Doppler color flow evaluation [40]. 


\section{Conclusion}

Diagnosis of upper or lower deep venous thrombosis is made by clinicians and sonographers after a good clinical examination followed by radiological investigations such as Duplex USG, contrast venography, CT venography or MR venography. Duplex USG is the initial imaging modality of choice in the diagnosis of DVT. It is available, non-invasive and free of radiation however this investigation is operator dependent. Patients may be symptomatic or asymptomatic for DVT. Screening compression ultrasound is useful in patients with high risk for the disease. Sonographic findings of acute DVT include anechoic or hypoechoic thrombus and lack of venous compressibility. Chronic DVT is characterized by the presence of echogenic thrombus within the vessel's lumen with partial compressibility and peripheral revascularization or collaterals seen on duplex USG. Duplex USG shows limitation to diagnose thrombosis in brachiocephalic vein or super vena cava for the upper extremities as well in pelvic deep veins or inferior vena cava for lower extremities therefore other radiological investigations such as contrast venography or Magnetic Resonance Venography are recommended. Studies have shown that Duplex USG remains a rapid, accurate and noninvasive technique in the evaluation of venous thrombosis in both upper and lower limbs.

\section{Acknowledgments}

I'm very grateful to Honorable Dr Jonathan Lusi, the Legal Representative of HEAL AFRICA Hospital for encouragement in research. My thanks go to Dr Murray, Mme Sue Reid and AUSHEAL for the support of my studies (Masters of Medicine in Radiology) at Makerere University and support of our radiology department.

\section{References}

1. Kesieme E, Kesieme C, Jebbin N, Irekpita E, Dongo A (2011) Deep vein thrombosis: a clinical review. J Blood Med 2: 59-69. Link: http://bit.ly/20MISyz

2. Streiff MB, Bockenstedt PL, Cataland SR, Chesney C, Eby C, et al. (2011) Venous Thromboembolic Disease. J Natl Compr Canc Netw 9: 714-777. Link: http://bit.ly/2HibeMw

3. Drake R, Vogl AW, Mitchell A (2009) Gray's anatomy for Students. International Edition. With Student Consult 1136. Link: http://bit.ly/2HcvdMq

4. Caggiati A, Bergan JJ, Gloviczki P, Eklof B, Allegra C, et al. (2005) Nomenclature of the veins of the lower limb: extensions, refinements, and clinical application. J Vasc Surg 41: 719-724. Link: http://bit.ly/3btWJTy

5. Oğuzkurt L (2012) Ultrasonographic anatomy of the lower extremity superficial veins. Diagn Interv Radiol 18: 423-430. Link: http://bit.ly/2SBuKZA

6. Friedman AC (2006) Diagnostic ultrasound. 3rd ed. Vol 1 and 2. Am J Roentgenol 187: W139. Link: http://bit.ly/37fZyEB

7. Previtali E, Bucciarelli P, Passamonti SM, Martinelli I (2011) Risk factors for venous and arterial thrombosis. Blood Transfus 9: 120-138. Link: http://bit.ly/2vtxTT6

8. Anderson FA, Spencer FA (2003) Risk Factors for Venous Thromboembolism. Circulation 107: 9-16. Link: http://bit.ly/2SBvjCG

9. Urbano FL (2001) Homans' Sign in the Diagnosis of Deep Venous Thrombosis. Hospital Physician 22-24. Link: http://bit.ly/2SFVeZI
10. Baglin T, Luddington R, Brown K, Baglin C (2003) Incidence of recurrent venous thromboembolism in relation to clinical and thrombophilic risk factors: prospective cohort study. Lancet 362: 523-526. Link: http://bit.ly/2OMMEHQ

11. Kahn SR (1998) The Clinical Diagnosis of Deep Venous Thrombosis: Integrating Incidence, Risk Factors, and Symptoms and Signs. Arch Intern Med 158: 2315-2323. Link: http://bit.ly/2SJc4rO

12. Kelly J, Hunt BJ (2003) The utility of pretest probability assessment in patients with clinically suspected venous thromboembolism. J Thromb Haemost 1 : 1888-1896. Link: http://bit.ly/3buUhwb

13. Vululi ST, Bugeza S, Zeridah M, Ddungu H, Openy AB, et al. (2018) Prevalence of lower limb deep venous thrombosis among adult HIV positive patients attending an outpatient clinic at Mulago Hospital. AIDS Res Ther 15: 3. Link: http://bit.ly/2SFBw0b

14. Lee DK, Ahn KS, Kang CH, Cho SB (2017) Ultrasonography of the lower extremity veins: anatomy and basic approach. Ultrasonography 36: 120-130. Link: http://bit.ly/37iQOgM

15. Swanson E (2015) Ultrasound screening for deep venous thrombosis detection: a prospective evaluation of 200 plastic surgery outpatients. Plast Reconstr Surg Glob Open 3: e332. Link: http://bit.ly/2HidQKk

16. Grant JD, Stevens SM, Woller SC, Lee EW, Kee ST, et al. (2012) Diagnosis and management of upper extremity deep-vein thrombosis in adults. Thromb Haemost 108: 1097-1108. Link: http://bit.ly/2uurZRW

17. Tan M, van Rooden CJ, Westerbeek RE, Huisman MV (2009) Diagnostic management of clinically suspected acute deep vein thrombosis. $\mathrm{Br} \mathrm{J}$ Haematol 146: 347-360. Link: http://bit.ly/31LJUzz

18. Blaivas M, Lambert MJ, Harwood RA, Wood JP, Konicki J (2000) Lowerextremity Doppler for Deep Venous Thrombosis-Can Emergency Physicians Be Accurate and Fast? Acad Emerg Med 7: 120-126. Link: http://bit.ly/31SuLMT

19. Zierler BK (2004) Ultrasonography and diagnosis of venous thromboembolism Circulation 109: 19-I14. Link: http://bit.ly/2ULKyf4

20. Palareti G (2014) How I treat isolated distal deep vein thrombosis (IDDVT) Blood 123: 1802-1809. Link: http://bit.ly/37g1f4V

21. Rose SC, Nelson TR (2004) Ultrasonographic Modalities to Assess Vascular Anatomy and Disease. J Vasc Interv Radiol 15: 25-38. Link: http://bit.ly/39vZfaf

22. Tan M, van Rooden CJ, Westerbeek RE, Huisman MV (2009) Diagnostic management of clinically suspected acute deep vein thrombosis. $\mathrm{Br} \mathrm{J}$ Haematol 146: 347-360. Link: http://bit.ly/31LJUzz

23. Chin EE, Zimmerman PT, Grant MD EG (2005) Sonographic Evaluation of Upper Extremity Deep Venous Thrombosis. Journal of Ultrasound in Medecine 24: 829-838. Link: http://bit.ly/31KAMv0

24. Weber TM, Lockhart ME, Robbin ML (2007) Upper Extremity Venous Doppler Ultrasound. Radiologic Clinics of North America 45: 513-524. Link: http://bit.ly/2HcPh1l

25. Klok FA, Tan M, Huisman MV (2009) Ultrasound-based diagnostic strategies for deep vein thrombosis. JAMA 301: 933-934. Link: http://bit.ly/37lnDd9

26. Kearon C, Julian JA, Newman TE, Ginsberg JS (1998) Noninvasive Diagnosis of Deep Venous Thrombosis. Ann Intern Med 128: 663-677. Link: http://bit.ly/2UQUK5I

27. Johnson BF, Manzo RA, Bergelin RO, Strandness DE (1995) Relationship between changes in the deep venous system and the development of the post thrombotic syndrome after an acute episode of lower limb deep vein thrombosis: A one- to six-year follow-up. J Vasc Surg 21: 307-312. Link: http://bit.ly/2vpGK8u

28. Tovey C, Wyatt S (2003) Diagnosis, investigation, and management of deep vein thrombosis. BMJ 326: 1180-1184. Link: http://bit.ly/37iylM6 
29. Hamper UM, DeJong MR, Scoutt LM (2007) Ultrasound Evaluation of the Lower Extremity Veins. Radiol Clin North Am 45: 525-547. Link: http://bit.ly/2OLfpEL

30. Glajchen N, Shapiro RS (1997) Underassessment of lower extremity deep venous thrombosis using color flow Doppler compared to compression sonography. Computerized Medical Imaging and Graphics 21: 331-335. Link: http://bit.ly/39rrlTP

31. Barleben A, Bandyk DF (2013) Interpretation of peripheral venous duplex testing. Semin Vasc Surg 26: 111-119. Link: http://bit.ly/37g3Hs9

32. Malhotra S, Punia VPS (2004) Upper Extremity Deep Vein Thrombosis. JAPI 52: 237-241. Link: http://bit.ly/3bwbCET

33. Karande GY, Hedgire SS, Sanchez Y, Baliyan V, Mishra V, et al. (2016) Advanced imaging in acute and chronic deep vein thrombosis. Cardiovasc Diagn Ther 6 : 493-507. Link: http://bit.ly/2vpHPNA

34. Baarslag H, van Beek EJ, Koopman MM, Reekers JA (2002) Prospective Study of Color Duplex Ultrasonography Compared with Contrast Venography in Patients Suspected of Having Deep Venous Thrombosis of the Upper Extremities. Ann Intern Med 136: 865-872. Link: http://bit.ly/39w1udF
35. Joffe HV, Goldhaber SZ (2002) Upper-Extremity Deep Vein Thrombosis Circulation 106: 1874-1880. Link: http://bit.ly/2HcGYCG

36. Jacobson AF (2001) Diagnosis of deep venous thrombosis. A review of radiologic, radionuclide, and non-imaging methods. Q J Nucl Med 45: 324-333. Link: http://bit.ly/39vO2Xg

37. Kassaï B, Boissel JP, Cucherat M, Sonie S, Shah NR, et al. (2004) A systematic review of the accuracy of ultrasound in the diagnosis of deep venous thrombosis in asymptomatic patients. Thromb Haemost 91: 655-666. Link: http://bit.ly/39pM6zl

38. Rosen CL, Tracy JA (2001) The diagnosis of lower extremity deep venous thrombosis. Emergency Medicine Clinics 19: 895-912. Link: http://bit.ly/2wdolqF

39. Agnelli G, Radicchia S, Nenci GG (1995) Diagnosis of Deep Vein Thrombosis in Asymptomatic High-Risk Patients. Haemostasis 25: 40-48. Link: http://bit.ly/39rsVVL

40. Kearon C, Ginsberg JS, Hirsh J (1998) The Role of Venous Ultrasonography in the Diagnosis of Suspected Deep Venous Thrombosis and Pulmonary Embolism. Ann Intern Med 129: 1044-1049. Link: http://bit.ly/3byG0yi
Discover a bigger Impact and Visibility of your article publication with

Peertechz Publications

\section{Highlights}

* Signatory publisher of ORCID

* Signatory Publisher of DORA (San Francisco Declaration on Research Assessment)

* Articles archived in worlds' renowned service providers such as Portico, CNKI, AGRIS, TDNet, Base (Bielefeld University Library), CrossRef, Scilit, J-Gate etc.

* Journals indexed in ICMJE, SHERPA/ROMEO, Google Scholar etc.

* OAI-PMH (Open Archives Initiative Protocol for Metadata Harvesting)

* Dedicated Editorial Board for every journal

* Accurate and rapid peer-review process

* Increased citations of published articles through promotions

* Reduced timeline for article publication

Submit your articles and experience a new surge in publication services (https://www.peertechz.com/submission).

Peertechz journals wishes everlasting success in your every endeavours.

Copyright: @ 2020 Sosthène TV, et al. This is an open-access article distributed under the terms of the Creative Commons Attribution License, which permits unrestricted use, distribution, and reproduction in any medium, provided the original author and source are credited. 